\title{
Evaluation of CLIGEN Precipitation Parameters AND THEIR IMPLICATION ON WEPP RUNOFF AND EROSION PREDICTION
}

\author{
X. C. Zhang, J. D. Garbrecht
}

\begin{abstract}
The quality of synthesized daily weather data directly affects the output of hydrological and agricultural response models. The objectives of this study were to evaluate the ability of the CLIGEN model to reproduce daily, monthly, and annual precipitation amounts, extremes, and internal storm patterns (i.e., storm duration, relative peak intensity, and time to peak) and to assess further the impact of generated storm patterns on WEPP runoff and erosion prediction. Four Oklahoma stations with more than 50 years of daily precipitation data and eight other sites across the U.S. with an average record of 10 years of measured storm patterns were used. Mean absolute relative errors for simulating daily, monthly, and annual precipitation across the four Oklahoma stations were 4.7\%, 1.7\%, and 1.5\% for the means and 3.7\%, 6.7\%, and 15\% for the standard deviations, respectively. Mean absolute relative errors for the all-time maxima of daily, monthly, and yearly precipitation were $17.7 \%, 8.9 \%$, and $6.5 \%$, respectively. Storm pattern generation, especially storm duration, was determined to need improvement for better prediction of runoff and soil erosion. The measured storm patterns showed positive linear correlations between precipitation, duration, and relative peak intensity, but little correlation was shown for generated storm patterns. The CLIGEN-generated durations were generally too long for small storms and too short for large storms. Inaccurate storm pattern generation led to WEPP prediction errors as high as 35\% for average annual runoff and 47\% for annual sediment yield on the test sites. To improve WEPP runoff and erosion prediction, storm duration generation should be reconsidered, and a distribution-free approach may be used to induce proper correlations between the input storm variables.
\end{abstract}

Keywords. CLIGEN, Climate generator, Erosion prediction, Model evaluation, WEPP.

$\mathrm{D}$ aily precipitation series are needed to drive physically based hydrological and natural resource management models. A number of stochastic daily weather generators have been developed to meet this need, among which CLIGEN (Nicks et al., 1995) and USCLIMATE (Hanson et al., 1994) are commonly used. The synthetic generation of daily weather is useful in cases when the measured data record is too short or there are considerable amounts of missing data. These models can also be used to generate daily series for ungauged areas through spatial interpolation of model parameters from adjacent gauged sites. More importantly, these models are capable of generating a spectrum of daily weather series by adjusting model parameters, which is critical to assess responses of hydrological and natural resources to climate change (Wilks, 1992; Katz, 1996). A long-term measured climate dataset is often insufficient to conduct such impact studies because it only provides one realization out of a spectrum of possible climate scenarios.

Article was submitted for review in July 2002; approved for publication by the Soil \& Water Division of ASAE in November 2002.

The authors are Xunchang (John) Zhang, Research Hydrologist, and Jurgen D. Garbrecht, Hydraulic Engineer, USDA-ARS Grazinglands Research Laboratory, El Reno, Oklahoma. Corresponding author: Dr. Xunchang Zhang, USDA-ARS-GRL, 7207 W. Cheyenne Street, El Reno, OK 73036; phone: 405-262-5291; fax: 405-262-0133; e-mail: jzhang@ grl.ars.usda.gov.
Several evaluation and validation studies using various versions of CLIGEN and USCLIMATE have been reported in the literature. Johnson et al. (1996) conducted a thorough evaluation and comparison between the two models at six locations dispersed across the contiguous U.S. and concluded that annual and monthly precipitation statistics including means, standard deviations, and extremes were adequately replicated by both models. But daily amounts, particularly extreme amounts in any given year, were not entirely satisfactorily generated by either model. They further reported that the first-order Markov models used in both models adequately replicated sequences of wet and dry days. Wallis and Griffiths (1995) evaluated the WXGEN model at five Texas locations. The WXGEN model, which is a hybrid of CLIGEN and USCLIMATE, has the same precipitation occurrence and daily precipitation generation algorithms as in CLIGEN. The daily and monthly precipitation generations were found less satisfactory compared with findings reported by Johnson et al. (1996). Headrick and Wilson (1997), who evaluated CLIGEN daily weather parameters at five Minnesota locations, found that CLIGEN replicated daily precipitation amount reasonably well, but the storm duration was not satisfactorily generated. The Water Erosion Prediction Project (WEPP) model (Flanagan and Nearing, 1995) uses CLIGEN to generate daily weather input. Most validation studies for evaluating WEPP runoff and soil erosion predictions were conducted using measured precipitation amounts and storm patterns (i.e., storm duration, relative peak intensity, and time to peak intensity) to circumvent uncertainty introduced by CLIGEN (Zhang et al., 1996; Ghidey et al., 
1995; Kramer and Alberts, 1995). Comparisons of WEPP runoff and soil loss predictions using CLIGEN-generated versus measured storm patterns are useful to quantify prediction errors associated with storm pattern generation.

Recently, a number of major changes were made to the CLIGEN model (Flanagan et al., 2001). Yu (2000) uncovered a unit conversion error, which made the generated relative peak intensity and storm duration irresponsive to geographical locations. Correcting this error resulted in considerable changes in generated relative peak intensity and storm duration. The newly generated storm duration became extremely large and had to be halved to be comparable with the measured storm duration on 14 U.S. sites. Streams of uniform random numbers and standard normal deviates are basic ingredients for stochastic weather generators, and the quality of these random variates directly affects the quality of model outputs. A new subroutine was introduced to generate a month's worth of random numbers for each parameter at a time and to impose confidence interval tests on both the mean and standard deviation of generated normal deviates to control data quality (Flanagan et al., 2001). The tests are conducted on the numbers produced since the first day of simulation for the current month and parameter. The critical confidence interval was internally set to $50 \%$ in CLIGEN v5.107. This means that a certain number of datasets being tested would be rejected, and the rejected subsets often contain extremes or abnormal clusters of normal deviates. Thus, such data screening definitely alters the model output, especially extreme values. Numerous errors in the five raw databases that are used to derive input parameters for driving CLIGEN were discovered and corrected (Scheele and Hall, 2000). Corrections were made for improper data formats, erroneous data values, and inaccurate station locations detected in the raw databases. A search routine used to find nearby stations for parameter triangulation or spatial interpolation was refined. These changes have resulted in considerable changes in parameter values of many locations (Flanagan et al., 2001), which are used by CLIGEN for daily weather generation.

Among the commonly used stochastic daily weather generators, CLIGEN is the only one that generates internal storm patterns (i.e., storm duration, time to peak, and peak intensity), which are needed by many physically based hydrological and natural resource models. However, there has been little systematic evaluation of CLIGEN-generated storm patterns and their impact on WEPP runoff and soil loss predictions (Yu, 2000). The objectives of this study were to evaluate the reproducibility of the CLIGEN model in generating daily, monthly, and yearly precipitation amounts as well as storm patterns at four Oklahoma stations, and to quantify further the impact of generated storm patterns on WEPP-predicted runoff and soil loss as opposed to measured storm patterns at eight locations dispersed across the central and eastern U.S.

\section{Cligen (v5.107) Storm Generation}

The CLIGEN model generates daily precipitation occurrence, amount, duration, peak storm intensity, time to peak, and daily values of maximum, minimum, and dew point temperatures, solar radiation, and wind speed and direction on a monthly basis. Only precipitation and storm pattern generations are presented here. Parameter values used by CLIGEN to generate daily weather data at a particular station are derived as follows. Probabilities of precipitation occurrences of a wet day following a wet day and a wet day following a dry day, and mean, standard deviation, and the skewness (skew) coefficient of daily precipitation of each month are directly extracted from the station daily precipitation record. The mean $0.5-\mathrm{h}$ maximum precipitation depths $\left(\mathrm{R}_{0.5 \mathrm{max}}\right.$, the mean of annual maxima for each month) are triangulated with three adjacent stations selected from the CLIGEN database of 142 U.S. stations, using proximity to the target station for weighting. Time-to-peak parameter is also estimated by triangulation, which will be discussed in more detail later.

A first-order two-state Markov chain is used to generate precipitation occurrence for a day given the previous day being wet or dry. If a random number that is drawn from a uniform distribution for each day is less than the precipitation probability for the given previous day status, a precipitation event is predicted. For a predicted rain day, a skewed normal distribution is used to generate daily precipitation amounts for each month (Nicks and Lane, 1989):

$$
x=\frac{6}{g}\left\{\left[\frac{g}{2}\left(\frac{R-\mu}{s}\right)+1\right]^{1 / 3}-1\right\}+\frac{g}{6}
$$

where

$x=$ standard normal variate

$R=$ daily precipitation amount

$\mu=$ mean of the daily amounts for the month

$s=$ standard deviation of the daily amounts for the month

$g$ = skew coefficient of the daily amounts for the month. Two random numbers are used to generate the normal deviate $(x)$, which is then used in equation 1 to compute the daily amount $(R)$.

Assuming rainfall rates during a storm decrease exponentially from the maximum rate, Arnold and Williams (1989) proposed a method to estimate the peak storm intensity $\left(r_{p}\right)$ :

$$
r_{p}=-2 R \ln \left(1-\alpha_{0.5}\right)
$$

where $\alpha_{0.5}$ is a dimensionless quantity that is defined as the ratio of the maximum $0.5-\mathrm{h}$ rainfall depth $\left(R_{0.5}\right)$ to the daily rainfall amount $(R)$ for the event and is drawn from a two-parameter gamma distribution. The shape parameter of the gamma distribution is set to 6.28 in CLIGEN v5.107, and the other parameter is the mean $\alpha_{0.5}$ for the month $\left(\alpha_{0.5}\right.$ mean $)$ and is estimated by:

$$
\alpha_{0.5 \text { mean }}=R_{0.5 \text { mean }} / R_{\text {mean }}
$$

where $R_{0.5 \text { mean }}$ and $R_{\text {mean }}$ are the means of $R_{0.5}$ and $R$ for the month, respectively. $R_{0.5}$ mean is related to $R_{0.5 \text { max }}$ by:

$$
R_{0.5 \text { mean }}=-R_{0.5 \max } / \ln F
$$

where $R_{0.5 \text { max }}$ is triangulated for the location and month, as discussed earlier, and $F$ is the exceedance probability for $R_{0.5}$ $\max$ and is estimated by (Yu, 2000):

$$
F=2 /(2 n+1)
$$

where $n$ is the average number of rain days for the month.

The storm duration $(D)$ is estimated as:

$$
D=-0.5 \Delta / \ln \left(1-\alpha_{0.5}\right)
$$


where $\Delta$ is set to 3.99 in $v 5.107$ based on a calibration conducted by Yu (2000) on 14 widely dispersed U.S. sites. A value of 4.607 was used for $\Delta$ in CLIGEN v4.2 and changed to 9.21 in later versions before setting to 3.99. Actually, in equation $6, \Delta$ is an overall mean of the relative peak intensity across all sites. Equations 2 and 6, as pointed out by Nicks et al. (1995), are tentative and subject to modification as more historical precipitation data are analyzed. Relative peak intensity $\left(i_{p}\right)$ is calculated as:

$$
i_{p}=r_{p} D / R
$$

Combining equations 7 and 2, we get:

$$
i_{p}=-2 D \ln \left(1-\alpha_{0.5}\right)
$$

Time-to-peak intensity is estimated by triangulating the time-to-peak cumulative distributions of three adjacent stations. Time to peak, calculated for each of the 1548 U.S. stations, is assigned to one of 12 classes of an equal interval. An accumulated distribution of time to peak of all storms throughout all years is developed by summing the fraction of the number events in each class. A site-specific time to peak for each storm can be generated by sampling the triangulated time-to-peak cumulative distribution for the target location with a uniform random number between 0 and 1 .

\section{Materials ANd Methods}

Four Oklahoma sites (Goodwell, Weatherford, Chandler, and Sallisaw) with mean annual precipitation ranging from 417 to $1153 \mathrm{~mm}$ were used to evaluate the reproducibility of CLIGEN for generating daily, monthly, and yearly precipitation, daily extremes, and frequencies of wet and dry periods (table 1). Daily precipitation time series (up to year 2000) measured at these stations by the National Weather Service (NWS) were used to derive CLIGEN input parameters. The derived parameter values were input into CLIGEN v5.107, and 100 years of daily values were then generated with the default random number seed and without interpolation. NWS-historical and CLIGEN-generated daily precipitation values were summed by month and year. Statistics including mean, standard deviation, coefficients of skewness and kurtosis, percentiles, and extreme values were calculated for both historical and generated data on daily, monthly, and annual bases. Relative error (RE), computed as the difference between generated and historical values divided by the historical value, was also calculated. A t-test and F-test were used to test the equality of means and standard deviations, respectively, for generated and historical annual precipitation amounts at a site. A significance level of $\mathrm{P}=0.01$ was used in the tests. Generally, $\mathrm{t}-$ tests are based on the normality and equal-variance assumptions. These requirements may be relaxed when the sample sizes are large. As stated by Ott (1988, p. 183), "When the assumptions of normality and equal variances are not valid but the sample sizes are large, the results using a t-test are approximately correct." As indicated by the central limit theorem and the relatively small skewness and kurtosis coefficients of the annual precipitation series (see statistics later), these tests are deemed acceptable. In addition, two nonparametric tests, the Wilcoxon rank sum and the Kolmogorov-Smirnov (K-S) tests, which are applicable to any distribution, were used to test the null hypothesis that two populations are identical.

In addition to daily precipitation data from NWS, Oklahoma Mesonet data (www.mesonet.ou.edu) including daily precipitation amounts, number of 5-min rain intervals, and maximum 5-min rainfall rates from 1994 to 2000 at these four Oklahoma locations were also used to evaluate storm patterns. The short Mesonet record limits the extension of the results, but it supports a first-order check on the model-generated patterns. Effective rainfall duration was calculated by summing the nonzero rainfall intervals in a given day. Relative peak intensity $\left(i_{p}\right)$ was calculated by dividing the maximum 5-min rainfall intensity by the average rainfall intensity of the storm. The 5, 15, 25, 50, 75, 95, and 99 percentiles of daily precipitation, storm duration, and relative peak intensity of the Mesonet data were calculated and compared to those computed with the CLIGEN-generated 100 years of daily values, as described earlier. The scaled percentiles as divided by the Mesonet means for both sets were plotted for semi-quantitative comparison.

Climate data from the remaining sites (table 1), which contain measured daily precipitation, effective rainfall duration, time to peak, and relative peak intensity as developed by Risse et al. (1995), were used to run the WEPP model. The other WEPP input files included soil, slope, and crop management. Soil properties and topography of an experimental plot located at El Reno, Oklahoma, were used to build the soil and slope input files for use at all sites. The soils in the field plot were primarily silt loam, and had, on average, $24 \%$ sand, $23 \%$ clay, and a saturated hydraulic conductivity of about $7 \mathrm{~mm} / \mathrm{h}$. The average slope was $3.5 \%$

\begin{tabular}{|c|c|c|c|c|c|c|}
\hline Site & Station & $\begin{array}{l}\text { Latitude } \\
\left({ }^{\circ} \mathrm{N}\right)\end{array}$ & $\begin{array}{l}\text { Longitude } \\
\left({ }^{\circ} \mathrm{W}\right)\end{array}$ & $\begin{array}{l}\text { Elevation } \\
\text { (m) }\end{array}$ & Period & $\begin{array}{l}\text { Precipitation } \\
(\mathrm{mm} / \mathrm{yr})\end{array}$ \\
\hline Goodwell, Oklahoma[a] & Goodwell, OK & 36.60 & 101.62 & 1005 & $1948-2000$ & 417 \\
\hline Weatherford, Oklahoma ${ }^{[\mathrm{a}]}$ & Weatherford, OK & 35.53 & 98.70 & 499 & $1948-2000$ & 717 \\
\hline Chandler, Oklahoma[a] & Chandler, OK & 35.70 & 96.88 & 262 & $1902-2000$ & 885 \\
\hline Sallisaw, Oklahoma[a] & Sallisaw, OK & 35.47 & 94.78 & 161 & $1948-2000$ & 1153 \\
\hline Guthrie, Oklahoma & Guthrie, OK & 35.87 & 97.43 & 277 & $1942-56$ & 733 \\
\hline Bethany, Missouri & Bethany, MO & 40.25 & 94.03 & 277 & $1931-40$ & 742 \\
\hline Castana, Iowa & Castana 4E, IA & 42.07 & 95.82 & 438 & $1960-71$ & 735 \\
\hline Geneva, New York & Geneva, SCS, NY & 42.88 & 77.02 & 180 & $1937-46$ & 817 \\
\hline Holly Springs, Mississippi & Holly Springs EX ST MS & 34.82 & 89.43 & 146 & $1961-79$ & 1275 \\
\hline Madison, South Dakota & Madison, 1 WNW SD & 44.00 & 97.13 & 524 & $1962-70$ & 579 \\
\hline Morris, Minnesota & Morris WC School MN & 45.58 & 95.92 & 344 & $1962-71$ & 617 \\
\hline Tifton, Georgia & Tifton 2 N GA & 31.47 & 83.53 & 112 & $1959-66$ & 1231 \\
\hline
\end{tabular}

Table 1. Site location, station, record period, and average annual precipitation for the period.

[a] Sites used in detailed evaluation of daily, monthly, and yearly precipitation generation. 
and the slope length was $200 \mathrm{~m}$. A continuous soybean with fall-moldboard plow selected from the WEPP management database was used at the Guthrie and Geneva sites, and a continuous corn with fall-moldboard plow from the WEPP database was used at the remaining sites. For evaluating the effect of CLIGEN-generated storm patterns on WEPP runoff and soil loss predictions, measured daily values of precipitation and maximum and minimum temperatures were input into CLIGEN v5.107 for generating missing parameters, mainly storm patterns (i.e., duration, time to peak, and relative peak intensity). Except for the storm patterns, the generated and measured climate files including daily precipitation amounts were identical. The generated climate file along with the other three input files were used to run WEPP. Differences between measured and generated storm patterns were examined, and the resulting differences in WEPP runoff and soil loss predictions were compared.

\section{RESULTS}

The CLIGEN model tended to overpredict the daily precipitation means on all sites (table 2). The mean absolute RE of daily precipitation across all four Oklahoma sites was $4.7 \%$ for the means and $3.7 \%$ for the standard deviations. The largest differences occurred at the driest site (Goodwell), where the mean was overpredicted by $7.4 \%$ and the standard deviation was underpredicted by $-5.4 \%$. The distribution of daily precipitation was extremely skewed to the left, but the skewness was reasonably replicated with a mean absolute RE of $7.7 \%$ across all four sites. In general, an absolute skew coefficient of $>1$ is considered extremely skewed, between 0.5 to 1 moderately skewed, and $<0.5$ fairly symmetric (Evans and Olson, 2002, p. 65). The daily precipitation distribution was extremely peaked. The peakedness, as indicated by the kurtosis coefficient, was strikingly overpredicted at two of the four sites. Cumulative distributions of predicted and observed daily precipitation were relatively close, as indicated by the percentiles. Nevertheless, CLIGEN had a tendency to slightly overpredict daily amounts for small storms (less than 75 percentiles) and underpredict for larger storms. Maximum daily precipitation of any year was close at the Goodwell and Sallisaw sites but was more than $20 \%$ overpredicted on the other two sites, where kurtosis coefficients were also markedly overpredicted. The mean number of raindays that received $\geq 1 \mathrm{~mm}$ rain per day was slightly underpredicted on all sites, with the maximum difference being $<3.5$ days at the wettest site (Sallisaw). The Wilcoxon rank sum and $\mathrm{K}-\mathrm{S}$ tests rejected the hypothesis that the two distributions are identical on all sites at very significant levels (table 2). These tests may be biased by the sample size. The tests are more suitable for a small sample size; when sample size becomes larger, as here, these tests become more stringent. This is partially reflected by the test results of annual precipitation, in which both non-parametric tests were insignificant (meaning that the null hypothesis was not rejected), although the absolute RE of standard deviations was 4 times greater for annual amounts than for daily amounts (see below). Daily precipitation was further tested on a monthly basis. Out of 48 month-location combinations, 16 for the Wilcoxon test and 26 for the $\mathrm{K}-\mathrm{S}$ test were rejected at $\mathrm{P}=0.01$.

Statistics on annual maximum daily precipitation, which is the maximum daily amount of each year, are given in table 3. The mean absolute RE across all four sites was $5.1 \%$ for the mean and $9.0 \%$ for the standard deviation. The standard deviation was poorly simulated at the Chandler site, with an RE of $24.3 \%$. The absolute REs on the remaining sites were less than $5 \%$. The distribution of the annual series of extreme values was much less skewed and peaked than that of the daily precipitation series. The 95 percentiles were similar at the Goodwell and Sallisaw sites, which was consistent with the maximum daily precipitation (of any year) predictions on the sites (see table 2). The REs of the 95 percentiles were $-7 \%$ at Weatherford and $18 \%$ at Chandler, which were quite large but were much smaller than the REs of the maximum daily precipitation on these sites. On all sites, the Wilcoxon and $\mathrm{K}-\mathrm{S}$ tests were insignificant at $\mathrm{P}=$ 0.01 , implying that distribution of annual maximum daily precipitation (table 3 ) was better simulated by the model than was daily precipitation (table 2).

Monthly mean precipitation of all months was well preserved with a mean absolute RE of $1.7 \%$ across all sites (table 4). The standard deviation was slightly underpredicted at all sites. The largest underprediction was $-10.1 \%$ at the Weatherford site. The degree of skewness and peakedness was much smaller than for daily values, as expected based on the central limit theorem. The skew and kurtosis coefficients

Table 2. Statistics of daily precipitation amounts and mean numbers of raindays by location and source for storms $>1 \mathrm{~mm}$ (NWS = NWS-historical, C = CLIGEN-generated).

\begin{tabular}{|c|c|c|c|c|c|c|c|c|}
\hline & \multicolumn{2}{|c|}{ Goodwell } & \multicolumn{2}{|c|}{ Weatherford } & \multicolumn{2}{|c|}{ Chandler } & \multicolumn{2}{|c|}{ Sallisaw } \\
\hline & NWS & $\mathrm{C}$ & NWS & $\mathrm{C}$ & NWS & $\mathrm{C}$ & NWS & $\mathrm{C}$ \\
\hline Mean (mm) & 9.4 & 10.1 & 13.0 & 13.1 & 14.0 & 14.5 & 15.5 & 16.6 \\
\hline Standard deviation (mm) & 11.1 & 10.5 & 16.3 & 15.7 & 16.5 & 16.7 & 17.3 & 16.5 \\
\hline Skew coefficient & 2.6 & 2.5 & 3.4 & 3.8 & 2.8 & 3.1 & 2.2 & 2.1 \\
\hline Kurtosis coefficient & 9.6 & 9.7 & 18.7 & 28.4 & 11.3 & 17.1 & 7.0 & 6.3 \\
\hline \multicolumn{9}{|l|}{ Percentiles (mm) } \\
\hline 25 & 2 & 3 & 3 & 4 & 3 & 4 & 4 & 5 \\
\hline 50 & 5 & 7 & 7 & 8 & 8 & 9 & 10 & 11 \\
\hline 75 & 12 & 13 & 17 & 17 & 19 & 19 & 21 & 23 \\
\hline 95 & 32 & 31 & 43 & 42 & 46 & 46 & 51 & 50 \\
\hline Maximum daily precipitation (mm) & 98 & 108 & 191 & 261 & 164 & 202 & 153 & 155 \\
\hline Mean number of raindays per year & 44.2 & 42.1 & 54.8 & 54.0 & 61.8 & 59.7 & 72.0 & 68.5 \\
\hline Wilcoxon P value & \multicolumn{2}{|c|}{0.0001} & \multicolumn{2}{|c|}{0.0014} & \multicolumn{2}{|c|}{0.0006} & \multicolumn{2}{|c|}{0.0001} \\
\hline Kolmogorov-Smirnov P value & \multicolumn{2}{|c|}{$<0.0001$} & \multicolumn{2}{|c|}{$<0.0001$} & \multicolumn{2}{|c|}{$<0.0001$} & \multicolumn{2}{|c|}{$<0.0001$} \\
\hline
\end{tabular}


Table 3. Statistics of annual maximum daily precipitation amounts by location and source (NWS = NWS-historical, C = CLIGEN-generated).

\begin{tabular}{|c|c|c|c|c|c|c|c|c|}
\hline & \multicolumn{2}{|c|}{ Goodwell } & \multicolumn{2}{|c|}{ Weatherford } & \multicolumn{2}{|c|}{ Chandler } & \multicolumn{2}{|c|}{ Sallisaw } \\
\hline & NWS & $\mathrm{C}$ & NWS & $\mathrm{C}$ & NWS & $\mathrm{C}$ & NWS & $\mathrm{C}$ \\
\hline Mean $(\mathrm{mm})$ & 50.1 & 47.4 & 80.2 & 74.4 & 81.1 & 82.2 & 84.1 & 78.6 \\
\hline Standard deviation $(\mathrm{mm})$ & 17.1 & 16.3 & 35.0 & 36.7 & 27.2 & 33.8 & 22.6 & 22.1 \\
\hline Skew coefficient & 0.8 & 1.2 & 1.2 & 2.4 & 0.9 & 1.8 & 1.0 & 0.9 \\
\hline Kurtosis coefficient & 0.2 & 1.7 & 1.4 & 8.1 & 1.0 & 3.7 & 1.0 & 1.3 \\
\hline 95 percentile $(\mathrm{mm})$ & 81 & 78 & 156 & 144 & 136 & 160 & 122 & 123 \\
\hline Wilcoxon $\mathrm{P}$ value & \multicolumn{2}{|c|}{0.369} & \multicolumn{2}{|c|}{0.254} & \multicolumn{2}{|c|}{0.677} & \multicolumn{2}{|c|}{0.176} \\
\hline Kolmogorov-Smirnov P value & \multicolumn{2}{|c|}{0.499} & \multicolumn{2}{|c|}{0.245} & \multicolumn{2}{|c|}{0.895} & \multicolumn{2}{|c|}{0.479} \\
\hline
\end{tabular}

Table 4. Statistics of monthly precipitation amounts by location and source (NWS = NWS-historical, C = CLIGEN-generated).

\begin{tabular}{|c|c|c|c|c|c|c|c|c|}
\hline & \multicolumn{2}{|c|}{ Goodwell } & \multicolumn{2}{|c|}{ Weatherford } & \multicolumn{2}{|c|}{ Chandler } & \multicolumn{2}{|c|}{ Sallisaw } \\
\hline & NWS & $\mathrm{C}$ & NWS & $\mathrm{C}$ & NWS & $\mathrm{C}$ & NWS & $\mathrm{C}$ \\
\hline Mean (mm) & 34.7 & 35.9 & 59.8 & 59.4 & 73.7 & 72.5 & 96.1 & 95.4 \\
\hline Standard deviation $(\mathrm{mm})$ & 38.7 & 37.2 & 58.1 & 52.2 & 64.0 & 59.6 & 67.7 & 63.8 \\
\hline Skew coefficient & 1.6 & 1.6 & 1.6 & 1.6 & 1.5 & 1.6 & 1.1 & 1.0 \\
\hline Kurtosis coefficient & 2.8 & 3.3 & 2.5 & 3.5 & 2.8 & 4.2 & 1.2 & 1.1 \\
\hline \multicolumn{9}{|l|}{ Percentiles (mm) } \\
\hline 25 & 5 & 8 & 19 & 21 & 28 & 30 & 44 & 48 \\
\hline 50 & 20 & 25 & 42 & 46 & 58 & 59 & 85 & 84 \\
\hline 75 & 54 & 54 & 82 & 82 & 100 & 99 & 136 & 131 \\
\hline 95 & 113 & 111 & 190 & 161 & 211 & 190 & 223 & 220 \\
\hline Maximum monthly precipitation (mm) & 234 & 252 & 350 & 338 & 411 & 507 & 367 & 363 \\
\hline Wilcoxon P value & \multicolumn{2}{|c|}{0.068} & \multicolumn{2}{|c|}{0.189} & \multicolumn{2}{|c|}{0.727} & \multicolumn{2}{|c|}{0.810} \\
\hline Kolmogorov-Smirnov P value & \multicolumn{2}{|c|}{0.013} & \multicolumn{2}{|c|}{0.123} & \multicolumn{2}{|c|}{0.907} & \multicolumn{2}{|c|}{0.278} \\
\hline
\end{tabular}

Table 5. Statistics of annual precipitation amounts by location and source (NWS = NWS-historical, C = CLIGEN-generated).

\begin{tabular}{|c|c|c|c|c|c|c|c|c|}
\hline & \multicolumn{2}{|c|}{ Goodwell } & \multicolumn{2}{|c|}{ Weatherford } & \multicolumn{2}{|c|}{ Chandler } & \multicolumn{2}{|c|}{ Sallisaw } \\
\hline & NWS & $\mathrm{C}$ & NWS & $\mathrm{C}$ & NWS & $\mathrm{C}$ & NWS & $\mathrm{C}$ \\
\hline Mean (mm) & 417.0 & 430.6 & 717.1 & 712.7 & 884.5 & 869.9 & 1153.0 & 1144.2 \\
\hline Standard deviation (mm) & 94.3 & 91.6 & 180.3 & 155.8 & 203.8 & 174.1 & 268.6 & $189.9^{[\mathrm{a}]}$ \\
\hline Skew coefficient & 0.5 & -0.3 & 0.0 & 0.0 & 0.2 & 0.4 & 0.7 & 0.5 \\
\hline Kurtosis coefficient & 0.2 & -0.6 & -0.4 & -0.2 & 0.0 & -0.4 & 0.9 & 0.2 \\
\hline \multicolumn{9}{|l|}{ Percentiles (mm) } \\
\hline 25 & 360 & 364 & 615 & 610 & 742 & 735 & 939 & 1003 \\
\hline 50 & 409 & 439 & 705 & 703 & 871 & 861 & 1142 & 1111 \\
\hline 75 & 459 & 498 & 847 & 825 & 1016 & 986 & 1295 & 1274 \\
\hline 95 & 553 & 577 & 1000 & 957 & 1272 & 1156 & 1630 & 1469 \\
\hline Maximum annual precipitation (mm) & 660 & 605 & 1110 & 1074 & 1394 & 1318 & 1928 & 1772 \\
\hline Wilcoxon P value & \multicolumn{2}{|c|}{0.662} & \multicolumn{2}{|c|}{0.426} & \multicolumn{2}{|c|}{0.585} & \multicolumn{2}{|c|}{0.992} \\
\hline Kolmogorov-Smirnov P value & \multicolumn{2}{|c|}{0.393} & \multicolumn{2}{|c|}{0.393} & \multicolumn{2}{|c|}{0.919} & \multicolumn{2}{|c|}{0.240} \\
\hline
\end{tabular}

[a] Significantly different from the historical data at $\mathrm{P}=0.01$, using a t-test for means and $\mathrm{F}$-test for standard deviations.

were well simulated on all sites, except for kurtosis at the Weatherford and Chandler sites. There was no consistent trend of bias with percentiles across all sites. The maximum monthly precipitation of any year was adequately simulated on all sites with the absolute ER $<8 \%$, except on the Chandler site where CLIGEN overpredicted it by $23 \%$. The Wilcoxon and $\mathrm{K}-\mathrm{S}$ tests were insignificant at $\mathrm{P}=0.01$ on all sites (table 4). Monthly precipitation was also tested by month on each location (48 combinations). All the Wilcoxon and $\mathrm{K}-\mathrm{S}$ tests for distributions were insignificant at $\mathrm{P}=0.01$.

Mean annual precipitation on the four sites, ranging from 417 to $1153 \mathrm{~mm}$, was satisfactorily simulated with a mean absolute RE of $1.5 \%$ (table 5). The CLIGEN model consistently underpredicted standard deviation by a mean of $-15 \%$ ranging from $-3 \%$ to $-29 \%$. The underprediction of variance was much greater for annual than for monthly values. The coefficients of skewness and kurtosis were near zero, signifying an approximate normal distribution. There were no consistent patterns across sites regarding the percentile predictions. The maximum annual precipitation was consistently underpredicted with a mean RE of $-6.5 \%$ ranging from $-3 \%$ to $-10 \%$. Despite the fact that standard deviation was underpredicted by a mean of $-15 \%$, none of the Wilcoxon and $\mathrm{K}-\mathrm{S}$ tests was significant at $\mathrm{P}=0.01$, indicating the previously mentioned sample size effect on the test results.

Frequencies of measured and predicted wet and dry periods are plotted in figure 1 for the Sallisaw (wet) and Goodwell (dry) sites. Overall, the frequencies of both wet and dry periods were relatively well replicated by the model, indicating that the first-order two-state Markov chain model used in daily precipitation generation is adequate for use in Oklahoma. The frequency curves for the Weatherford and Chandler sites, which are not presented, fell between the curves of the two sites in figure 1, and the closeness of replication was similar to those presented. 

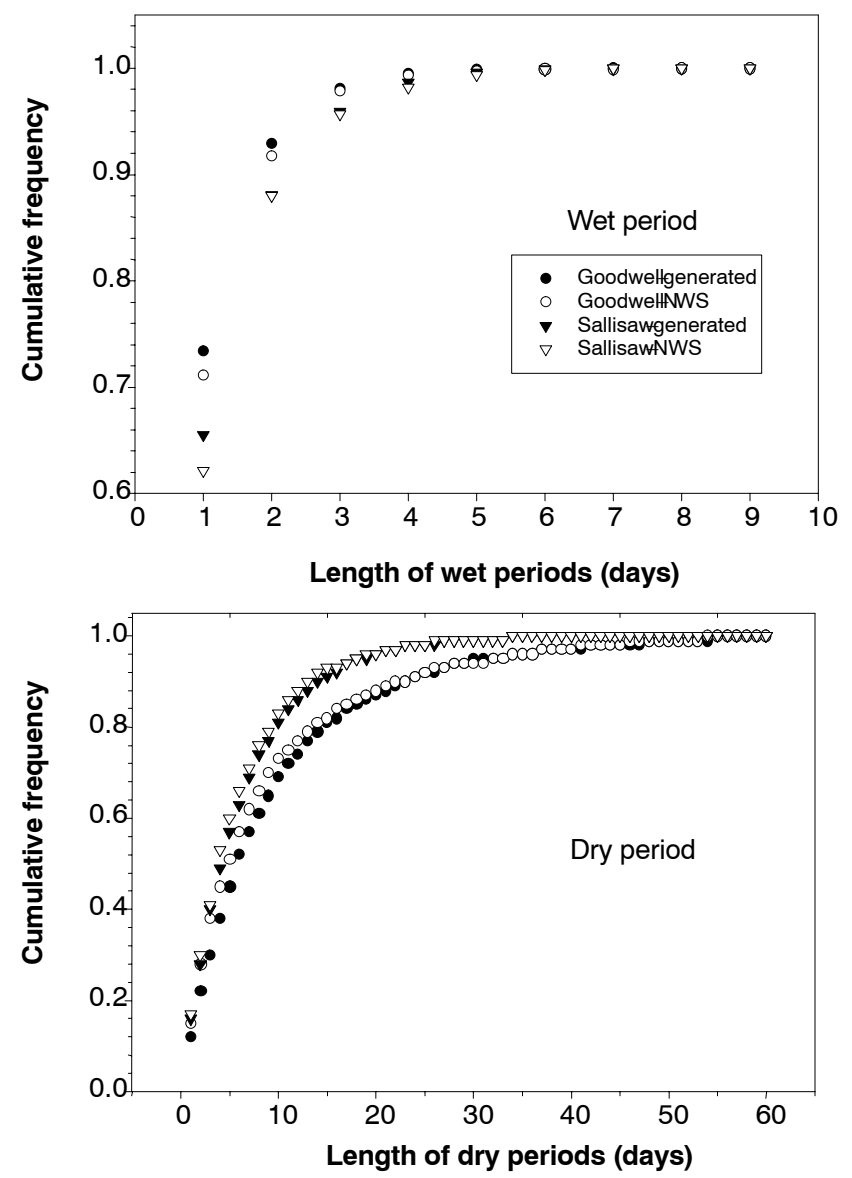

Figure 1. Frequency distributions of wet and dry periods extracted from 53 years of measured daily series of National Weather Service (NWS) and 100 years of CLIGEN-generated daily series on the Goodwell (dry) and Sallisaw (wet) sites.
Considering the nonstationary nature of climate, seven years of Mesonet historical data may not be long enough to warrant a quantitative comparison with 100 years of CLIGEN-generated data. Thus, the selected percentiles of daily precipitation $(>1 \mathrm{~mm})$, storm duration, and relative peak intensity as scaled by the corresponding Mesonet means are plotted in figure 2 for visual comparison. A data point of any percentile in figure 2 that is below the $1: 1$ line indicates that the CLIGEN-generated distribution, compared with the measured distribution, was shifted to a higher value at that probability level and therefore signifies an overprediction by CLIGEN, and vice versa. In general, daily precipitation was adequately replicated for this period on all sites, as indicated by the fact that precipitation percentiles are close to the 1:1 line. The CLIGEN-generated storm durations were too long for measured short storms (below 75 percentile) and too short for measured long storms. This pattern was consistent across all sites. The relative peak intensity $\left(i_{p}\right)$ was markedly overpredicted on all sites. The overprediction was in part caused by differences in the $i_{p}$ computation. The maximum peak intensity during a 5-min interval was used with the Mesonet data, while the hypothetical instantaneous peak intensity was used in CLIGEN. Another possible cause would be the inaccurate generation of storm duration. This is further explored below for eight different sites that have measured storm data.

For storms $>1 \mathrm{~mm}$, the mean measured and CLIGEN-generated storm durations were somewhat close (table 6); however, the standard deviations of CLIGEN-generated durations were consistently far smaller than those of measured durations on all sites. For storms $>10 \mathrm{~mm}$, the mean measured durations became longer, as expected; however, the mean generated durations remained similar to those generated for storms $>1 \mathrm{~mm}$, indicating that generated
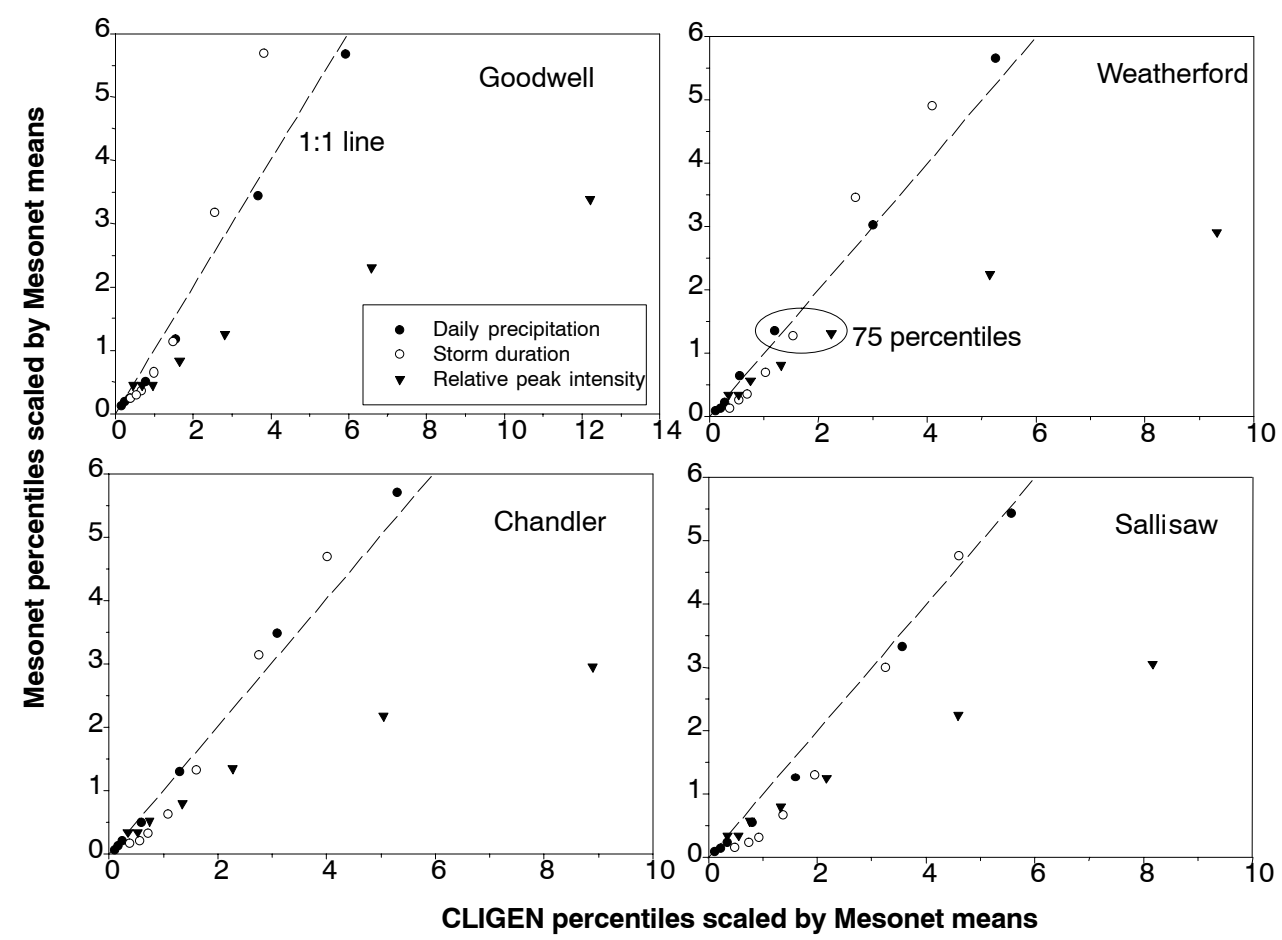

Figure 2. Scaled $5 \%, 15 \%, 25 \%, 50 \%, 75 \%, 95 \%$, and $99 \%$ percentiles of daily precipitation amounts, storm duration, and relative peak intensity from 7 years of Mesonet historical data and 100 years of CLIGEN-generated data on four sites. 
durations were largely independent of storm sizes. As a result, the differences between the measured and generated mean durations increased for storms $>10 \mathrm{~mm}$ as compared to storms $>1 \mathrm{~mm}$. The standard deviations of measured durations were larger for storms $>10 \mathrm{~mm}$ than for storms $>1$ $\mathrm{mm}$, while those of generated durations were similar. This resulted in a larger difference between the measured and generated durations for storms $>10 \mathrm{~mm}$ than for storms $>1$ $\mathrm{mm}$. The skewness and kurtosis of measured durations were far greater than those of generated durations for storms $>1$ $\mathrm{mm}$ except on the Guthrie and Tifton sites. The skew and kurtosis of measured durations became smaller for storms $>10 \mathrm{~mm}$, while those of generated durations were less changed. Results of the Wilcoxon tests showed that distributions of measured and generated storm durations were different at $\mathrm{P}=0.01$ at 7 sites (out of 8 ) for storms $>10 \mathrm{~mm}$ and 6 sites for storms $>1 \mathrm{~mm}$.

The means and standard deviations of generated relative peak intensities $\left(i_{p}\right)$ were closer to those of measured $i_{p}$ for storms $>1 \mathrm{~mm}$ than for storms $>10 \mathrm{~mm}$ (table 6). The means and standard deviations of measured $i_{p}$ were consistently smaller for storms $>1 \mathrm{~mm}$ than for storms $>10 \mathrm{~mm}$ on all sites, while those of generated $i_{p}$ were mixed. The skew and kurtosis coefficients of measured and generated $i_{p}$ were generally on the same order for storms $>1 \mathrm{~mm}$ and $>10 \mathrm{~mm}$.

For measured storm patterns, strong linear correlations between daily precipitation $(R)$, peak intensity $\left(r_{p}\right)$, duration $(D)$, and $i_{p}$ were exhibited on all sites (table 7). For generated storm patterns, strong correlations were shown between $R$ and $r_{p}$ and between $D$ and $i_{p}$, as $r_{p}$ was generated with

Table 6. Statistics of storm duration $(D)$ and relative peak intensity $\left(i_{p}\right)$ for storms $>1 \mathrm{~mm}$ and $>10 \mathrm{~mm}$ using measured and CLIGEN-generated storm patterns.

\begin{tabular}{|c|c|c|c|c|c|c|c|c|}
\hline \multirow[b]{3}{*}{ Site/Parameter } & \multicolumn{4}{|c|}{ Storms > $1 \mathrm{~mm}$} & \multicolumn{4}{|c|}{ Storms $>10 \mathrm{~mm}$} \\
\hline & \multicolumn{2}{|c|}{ Measured } & \multicolumn{2}{|c|}{ Generated } & \multicolumn{2}{|c|}{ Measured } & \multicolumn{2}{|c|}{ Generated } \\
\hline & $D$ & $i_{p}$ & $D$ & $i_{p}$ & $D$ & $i_{p}$ & $D$ & $i_{p}$ \\
\hline \multicolumn{9}{|l|}{ Bethany, Missouri } \\
\hline Mean (mm) & 3.57 & 5.29 & 2.74 & 4.85 & 5.66 & 6.98 & 2.76 & 4.98 \\
\hline Standard dev. (mm) & 3.54 & 4.59 & 1.55 & 4.35 & 4.26 & 4.99 & 1.60 & 4.16 \\
\hline Skew coefficient & 2.17 & 2.29 & 1.27 & 2.28 & 1.40 & 2.16 & 1.07 & 1.96 \\
\hline Kurtosis coefficient & 5.49 & 8.77 & 2.24 & 7.61 & 1.97 & 9.28 & 1.78 & 5.15 \\
\hline \multicolumn{9}{|l|}{ Castana, Iowa } \\
\hline Mean (mm) & 2.75 & 5.94 & 3.01 & 4.68 & 4.99 & 7.96 & 2.93 & 4.85 \\
\hline Standard dev. (mm) & 3.30 & 6.09 & 1.83 & 4.62 & 4.66 & 7.58 & 1.69 & 4.06 \\
\hline Skew coefficient & 3.35 & 3.87 & 1.73 & 3.37 & 1.88 & 3.73 & 1.31 & 2.80 \\
\hline Kurtosis coefficient & 15.81 & 29.13 & 5.12 & 19.60 & 5.43 & 25.63 & 2.74 & 14.00 \\
\hline \multicolumn{9}{|l|}{ Geneva, New York } \\
\hline $\operatorname{Mean}(\mathrm{mm})$ & 3.14 & 4.99 & 3.47 & 4.41 & 6.78 & 6.45 & 3.34 & 4.98 \\
\hline Standard dev. (mm) & 3.92 & 4.44 & 2.37 & 4.36 & 6.03 & 5.32 & 2.26 & 4.98 \\
\hline Skew coefficient & 2.74 & 2.15 & 1.63 & 2.55 & 1.02 & 1.90 & 1.65 & 2.51 \\
\hline Kurtosis coefficient & 8.32 & 6.74 & 5.42 & 8.86 & 0.30 & 4.66 & 4.16 & 8.42 \\
\hline \multicolumn{9}{|l|}{ Guthrie, Oklahoma } \\
\hline Mean (mm) & 3.38 & 5.48 & 2.48 & 5.40 & 5.09 & 7.10 & 2.46 & 5.11 \\
\hline Standard dev. (mm) & 3.40 & 4.46 & 1.64 & 5.40 & 4.22 & 5.12 & 1.73 & 4.70 \\
\hline Skew coefficient & 2.70 & 2.31 & 2.71 & 2.86 & 1.94 & 2.04 & 3.72 & 3.31 \\
\hline Kurtosis coefficient & 10.07 & 8.60 & 16.52 & 11.00 & 5.01 & 6.67 & 27.18 & 17.92 \\
\hline \multicolumn{9}{|c|}{ Holly Springs, Mississippi } \\
\hline Mean $(\mathrm{mm})$ & 2.48 & 6.07 & 2.93 & 4.89 & 3.34 & 6.84 & 2.94 & 4.76 \\
\hline Standard dev. (mm) & 3.25 & 5.42 & 1.78 & 4.55 & 4.37 & 6.22 & 1.66 & 4.19 \\
\hline Skew coefficient & 5.67 & 3.18 & 1.44 & 3.49 & 4.24 & 3.29 & 1.07 & 2.97 \\
\hline Kurtosis coefficient & 54.60 & 19.58 & 3.31 & 20.70 & 30.12 & 19.78 & 1.67 & 14.42 \\
\hline \multicolumn{9}{|l|}{ Madison, South Dakota } \\
\hline Mean $(\mathrm{mm})$ & 2.63 & 5.65 & 3.30 & 4.60 & 5.01 & 6.84 & 3.18 & 4.51 \\
\hline Standard dev. (mm) & 3.52 & 5.88 & 2.07 & 4.52 & 5.54 & 6.59 & 1.97 & 3.95 \\
\hline Skew coefficient & 3.60 & 2.68 & 1.41 & 2.16 & 1.72 & 1.99 & 1.65 & 1.87 \\
\hline Kurtosis coefficient & 14.34 & 10.15 & 2.87 & 6.28 & 2.29 & 4.53 & 4.36 & 5.21 \\
\hline \multicolumn{9}{|l|}{ Morris, Minnesota } \\
\hline Mean (mm) & 3.73 & 4.68 & 3.04 & 4.20 & 8.39 & 7.59 & 2.64 & 4.53 \\
\hline Standard dev. (mm) & 5.78 & 5.50 & 2.14 & 4.65 & 8.70 & 8.12 & 1.83 & 4.32 \\
\hline Skew coefficient & 3.52 & 4.07 & 1.63 & 3.39 & 1.72 & 3.15 & 2.06 & 2.68 \\
\hline Kurtosis coefficient & 14.69 & 29.75 & 3.81 & 17.71 & 3.23 & 16.17 & 7.56 & 10.77 \\
\hline \multicolumn{9}{|l|}{ Tifton, Georgia } \\
\hline Mean $(\mathrm{mm})$ & 3.39 & 6.37 & 2.45 & 5.35 & 5.64 & 7.42 & 2.52 & 5.35 \\
\hline Standard dev. (mm) & 4.26 & 5.12 & 1.80 & 6.30 & 5.43 & 5.69 & 1.99 & 7.42 \\
\hline Skew coefficient & 2.49 & 2.97 & 2.44 & 5.98 & 1.39 & 2.94 & 2.87 & 6.81 \\
\hline Kurtosis coefficient & 6.37 & 16.82 & 11.12 & 56.13 & 1.40 & 17.28 & 14.15 & 60.42 \\
\hline
\end{tabular}


Table 7. Correlation coefficients among daily precipitation $(R)$, storm duration $(D)$, peak intensity $\left(r_{p}\right)$, and relative peak intensity $\left(i_{p}\right)$ using measured and CLIGEN-generated storm patterns with $R>1 \mathrm{~mm}(\mathrm{M}=$ measured, $\mathrm{C}=\mathrm{CLIGEN}$-generated).

\begin{tabular}{|c|c|c|c|c|c|c|c|c|}
\hline \multirow[b]{2}{*}{ Site } & \multicolumn{2}{|c|}{$R$ vs. $r_{p}$} & \multicolumn{2}{|c|}{$R$ vs. $D$} & \multicolumn{2}{|c|}{$R$ vs. $i_{p}$} & \multicolumn{2}{|c|}{$D$ vs. $i_{p}$} \\
\hline & M & $\mathrm{C}$ & M & $\mathrm{C}$ & $\mathrm{M}$ & $\mathrm{C}$ & M & $\mathrm{C}$ \\
\hline Bethany & 0.69 & 0.75 & 0.53 & 0.11 & 0.32 & 0.05 & 0.31 & 0.42 \\
\hline Castana & 0.55 & 0.79 & 0.61 & -0.04 & 0.30 & 0.04 & 0.36 & 0.31 \\
\hline Geneva & 0.55 & 0.70 & 0.57 & -0.03 & 0.21 & 0.05 & 0.27 & 0.19 \\
\hline Guthrie & 0.44 & 0.61 & 0.61 & 0.07 & 0.33 & -0.01 & 0.37 & 0.55 \\
\hline Holly Springs & 0.56 & 0.68 & 0.36 & 0.10 & 0.13 & -0.04 & 0.37 & 0.47 \\
\hline Madison & 0.56 & 0.68 & 0.47 & 0.01 & 0.17 & 0.01 & 0.27 & 0.34 \\
\hline Morris & 0.59 & 0.75 & 0.58 & -0.10 & 0.39 & 0.03 & 0.27 & 0.07 \\
\hline Tifton & 0.60 & 0.70 & 0.68 & 0.11 & 0.30 & -0.03 & 0.32 & 0.56 \\
\hline Mean 1[a] & 0.56 & 0.71 & 0.57 & 0.03 & 0.26 & 0.01 & 0.31 & 0.36 \\
\hline Mean $2^{[b]}$ & 0.37 & 0.56 & 0.38 & 0.11 & 0.22 & 0.01 & 0.25 & 0.47 \\
\hline
\end{tabular}

[a] Mean of all sites for storms $>1 \mathrm{~mm}$.

[b] Mean of all sites for storms $>10 \mathrm{~mm}$.

equation 2 and $i_{p}$ with equation 8 . These results indicate that sampling the two-parameter gamma distribution for $\alpha_{0.5}$ in equations 2 and 8 generated proper correlations between these parameters. Little correlation was exhibited between $R$ and $D$ or between $R$ and $i_{p}$. The lack of correlation between $R$ and $i_{p}$ might have stemmed from the inaccurate generation of storm duration because $i_{p}$ is calculated with equation 7 . The correlation coefficients of measured storm patterns were all lower for storms $>10 \mathrm{~mm}$ than for storms $>1 \mathrm{~mm}$, as indicated by the means in the bottom row of table 7 , suggesting a storm size effect.

With all other parameters including $R$ being equal, the differential effects of measured vs. CLIGEN-generated $D, i_{p}$, and time to peak on WEPP-predicted runoff and soil loss are illustrated in table 8 . Based on a preliminary sensitivity analysis (data not shown), time to peak had the least impact on runoff and sediment generation among the three parameters. Relative errors were calculated as the predicted annual values with measured storm patterns minus those with generated storm patterns divided by those predicted with measured patterns. The WEPP model tended to overpredict surface runoff with CLIGEN-generated storm patterns, and the overprediction was as high as $35 \%$ at the Geneva site. This result indicates that shorter storm durations as generated for large storms by CLIGEN might have caused the overprediction of runoff. As a result, WEPP had a tendency to overpredict soil loss with generated storm patterns (5 out of 8 sites), compared to measured storm patterns. The largest overprediction was about $47 \%$ at the Geneva site. It should be noted that WEPP-predicted runoff and soil loss will be different when different soil, topography, and crop manage- ment are used in simulation. However, the trend of the runoff and soil loss responses to generated storm patterns would likely be the same.

\section{Discussion}

Means of daily, monthly, and annual precipitations were well generated by CLIGEN. The monthly precipitation means were better preserved than were the daily means. This is because CLIGEN consistently overpredicted daily means but underpredicted the number of raindays. The errors of overpredicting daily means tended to offset the errors of underpredicting raindays. The day-to-day variability as indicated by the standard deviation of daily precipitation was predicted fairly well, with the model capturing more than $95 \%$ of the variability of the measured daily values. Comparatively, the seasonal and interannual variability were less well simulated, as shown by the monthly and yearly standard deviations. The model captured $90 \%$ to $95 \%$ of measured monthly variability and $71 \%$ to $97 \%$ of yearly variability. Johnson et al. (1996) evaluated CLIGEN at six widely dispersed locations across the U.S. and found that CLIGEN captured $80 \%$ to $100 \%$ of interannual variability on these sites. The underprediction of interannual variability resulted from the simplifying assumption that climate, or more specifically the daily precipitation process as referred to here, is stationary. The nonstationary climate gives rise to additional low-frequency variability that is not explicitly simulated by the model. As commented by Wilks (1999), simple stationary models whose parameter statistics do not

Table 8. WEPP-predicted annual runoff and sediment yield using measured vs. CLIGEN-generated storm patterns, and their relative errors. ${ }^{\text {a] }}$

\begin{tabular}{|c|c|c|c|c|c|c|}
\hline \multirow[b]{2}{*}{ Site } & \multicolumn{3}{|c|}{ Mean Annual Runoff } & \multicolumn{3}{|c|}{ Mean Annual Sediment Yield } \\
\hline & $\begin{array}{l}\text { Measured } \\
(\mathrm{mm})\end{array}$ & $\begin{array}{l}\text { Generated } \\
(\mathrm{mm})\end{array}$ & $\begin{array}{c}\text { Error } \\
(\%)\end{array}$ & $\begin{array}{c}\text { Measured } \\
(\mathrm{Mg} / \mathrm{ha})\end{array}$ & $\begin{array}{c}\text { Generated } \\
\text { (Mg/ha) }\end{array}$ & $\begin{array}{c}\text { Error } \\
(\%)\end{array}$ \\
\hline Bethany & 80.2 & 91.4 & 14.0 & 21.7 & 26.2 & 20.6 \\
\hline Castana & 71.6 & 76.4 & 6.7 & 17.0 & 16.4 & -3.5 \\
\hline Geneva & 43.5 & 58.7 & 34.9 & 10.1 & 14.8 & 46.7 \\
\hline Guthrie & 121.5 & 141.9 & 16.8 & 52.0 & 59.1 & 13.7 \\
\hline Holly Springs & 300.5 & 299.5 & -0.3 & 58.7 & 52.9 & -9.9 \\
\hline Madison & 30.0 & 34.2 & 14.0 & 5.6 & 3.6 & -35.7 \\
\hline Morris & 40.6 & 53.9 & 32.8 & 7.6 & 10.5 & 38.2 \\
\hline Tifton & 243.8 & 288.7 & 18.4 & 43.5 & 60.3 & 38.6 \\
\hline
\end{tabular}

[a] Relative error $=$ (generated-measured) $/$ measured. 
change from year to year cannot fully replicate the variability of a nonstationary climate, and introduction of some degree of nonstationarity by conditioning specific parameters on covariates or simply choosing randomly is necessary to reproduce interannual variability while still using simple stationary models. Since probability of precipitation occurrence in each month varies from year to year, and that variation in large part causes fluctuations in monthly and annual precipitation, a probability distribution, rather than a constant value for each month as is used in CLIGEN, should be used. As a first approximation, a simple triangle distribution may be derived from station rainfall records, and a random sampling scheme may be used.

As opposed to findings reported by Johnson et al. (1996), annual maximum daily precipitation distribution was well simulated. However, the maximum daily precipitation of any year was more variable and less adequately generated. Predicted and measured maximum annual precipitations matched fairly well on all sites; however, there existed a consistent trend that CLIGEN underpredicted the annual maxima by $-3 \%$ to $-10 \%$ (table 5 ). Results from Johnson et al. (1996), who evaluated a CLIGEN version that had no normal deviate screening, showed that CLIGEN consistently overpredicted maximum annual precipitation on all eight sites up to $26 \%$. The discrepancy between the two studies might have been caused by the normal deviate screening introduced in v5.107. The confidence interval tests applied on both mean and standard deviation tend to reject sub-datasets that are "extremes." Thus, fewer extreme normal deviates would result in lower maximum annual precipitation. The CLIGEN model simulated the frequency of wet and dry periods relatively well, indicating that the first-order, two-state Markov chain is adequate for simulating precipitation occurrence. A similar conclusion was drawn by Wilks (1999) and Johnson et al. (1996) in their evaluation studies.

Generated storm duration $(D)$ and relative peak intensity $\left(i_{p}\right)$ differed greatly from measured values. On average, generated $D$ was too long for small storms and too short for large storms, as indicated by the smaller standard deviations, showing very weak dependency on storm sizes. Means of generated and measured durations were closer for storms $>1$ $\mathrm{mm}$ than for storms $>10 \mathrm{~mm}$. This was because a constant value of 3.99 used for $\Delta$ in equation 6 was derived from these sites using all storm events (Yu, 2000). Generated durations were not correlated to daily precipitation amounts $(R)$, suggesting that equation 6 is inadequate. As pointed out by Nicks et al. (1995), equation 6 is tentative in nature and needs to be further examined. The unsatisfactory prediction of $i_{p}$ by the CLIGEN model resulted from the inaccurate prediction of storm duration. To induce proper correlation among these input storm parameters, generation of $D$ should be conditioned on $R$, or a distribution-free (also called non-parametric) approach may be taken. The distribution-free approach involves sampling a joint distribution of $R$ and $D$, which may be developed directly using measured data or triangulated from nearby stations, with a multivariate sampling technique.

Predicted average annual runoff and sediment yield with generated storm patterns differed as much as $35 \%$ and $47 \%$, respectively. On an event basis, some of the differences were even greater. Disparities between generated $R$ and $D$ or $i_{p}$ as well as underprediction of storm duration for large storms are the main causes for the poor prediction. Thus, improving the CLIGEN storm pattern generation has great potential of enhancing WEPP runoff and soil loss predictions.

\section{Conclusions}

Means and standard deviations of daily precipitation amounts were adequately preserved by the CLIGEN model. Probability distributions of monthly and yearly precipitation were reasonably well reproduced by the model based on the Wilcoxon and Kolmogorov-Smirnov tests. However, the standard deviation of annual precipitation was consistently underpredicted by an average of $-15 \%$.

Annual maximum daily precipitation was well simulated by the model, but the all-time daily maxima were more variable, depending on location. Maximum monthly and yearly precipitations were adequately reproduced. However, due to the lack of consideration of climate nonstationarity, CLIGEN tended to underpredict interannual variability. To introduce some degree of nonstationarity, probability of precipitation occurrence should be modeled as a distribution rather than a constant value for each month.

There was little correlation among generated storm parameters. Generated duration was generally too long for small storms and too short for large storms. To induce proper correlations between the storm input parameters, a distribution-free approach may be used. Inaccurate prediction of storm patterns resulted in considerable errors in runoff and soil loss predictions. Improvement in storm pattern generation, especially storm duration, should greatly enhance WEPP runoff and soil loss prediction.

\section{ACKNOWLEDGEMENTS}

The authors would like to thank Bill Elliot and David Hall of the Rocky Mountain Research Station, USDA-Forest Service, Moscow, Idaho, for providing the CLIGEN-support parameterization computer programs, and Charles Meyer of the National Soil Erosion Research Lab, USDA-ARS, West Lafayette, Indiana, for making timely corrections to the CLIGEN model as advised by the authors. The authors would also like to thank Bofu Yu of Griffith University, Brisbane, Australia; Jeanne Schneider of the Grazinglands Research Lab, USDA-ARS, El Reno, Oklahoma; Y. C. Li of the Tropical Research and Education Center, University of Florida, Homestead, Florida; and three anonymous reviewers for their in-depth reviews and helpful comments.

\section{REFERENCES}

Arnold, J. G., and J. R. Williams. 1989. Stochastic generation of internal storm patterns. Trans. ASAE 32(1): 161-167.

Evans, J. R., and D. L. Olson. 2002. Introduction to Simulation and Risk Analysis. 2nd ed. Upper Saddle River, N.J.: Prentice Hall.

Flanagan, D. C., and M. A. Nearing, eds. 1995. USDA-Water Erosion Prediction Project: Hillslope Profile and Watershed Model Documentation. NSERL Report No. 10. West Lafayette, Ind.: USDA-ARS National Soil Erosion Research Lab.

Flanagan, D. C., C. R. Meyer, B. Yu, and D. L. Scheele. 2001. Evaluation and enhancement of the CLIGEN weather generator In Soil Erosion Research for the 21st Century: Proc. International Symposium, 107-110. J. C. Ascough II and D. C. Flanagan, eds. St. Joseph, Mich.: ASAE. 
Ghidey, F., E. E. Alberts, and L. Kramer. 1995. Comparison of runoff and soil loss predictions from the WEPP hillslope model to measured values for eight cropping and management treatments. ASAE Paper No. 952385. St. Joseph, Mich.: ASAE.

Johnson, G. L., C. L. Hanson, S. P. Hardegree, and E. B. Ballard. 1996. Stochastic weather simulation: Overview and analysis of two commonly used models. J. Applied Meteorology 35(10): 1878-1896.

Hanson, C. L., K. A. Cumming, D. A. Woolhiser, and C. W. Richardson. 1994. Microcomputer program for daily weather simulations in the contiguous United States. USDA-ARS Publ. ARS-114, Washington, D.C.: USDA-ARS.

Headrick, M. G., and B. N. Wilson. 1997. An evaluation of stochastic weather parameters for Minnesota and their impact on WEPP. ASAE Paper No. 972230. St. Joseph, Mich.: ASAE.

Katz, R. W. 1996. Use of conditional stochastic models to generate climate change scenarios. Climatic Change 32: 237-255.

Kramer, L. A., and E. E. Alberts. 1995. Validation of WEPP 95.1 daily erosion simulation. ASAE Paper No. 952385. St. Joseph, Mich.: ASAE.

Nicks, A. D., and L. J. Lane. 1989. Weather generator. Chapter 2 in USDA-Water Erosion Prediction Project: Hillslope Profile Version. L. J. Lane, and M. A. Nearing, ed. NSERL Report No. 2. West Lafayette, Ind.: USDA-ARS National Soil Erosion Research Laboratory.
Nicks, A. D., L. J. Lane, and G. A. Gander. 1995. Weather generator. Chapter 2 in USDA-Water Erosion Prediction Project: Hillslope Profile and Watershed Model Documentation. D. C. Flanagan and M. A. Nearing, eds. NSERL Report No. 10. West Lafayette, Ind.: USDA-ARS National Soil Erosion Research Laboratory.

Ott, L. 1988. An Introduction to Statistical Methods and Data Analysis. 3rd ed. Boston, Mass.: PWS-Kent.

Risse, L. M., M. A. Nearing, and X. C. Zhang. 1995. Variability in Green-Ampt effective hydraulic conductivity under fallow conditions. J. Hydrology 169: 1-24.

Scheele, D. L., and D. E. Hall. 2000. Corrections and improvements to the CLIGEN climate database. Moscow, Idaho: USDA Forest Service, Rocky Mountain Research Station.

Wallis, T. R., and J. F. Griffiths. 1995. An assessment of the weather generator (WXGEN) used in the erosion/productivity impact calculator (EPIC). Agric. and Forest Meteorology 73(1-2): 115-133.

Wilks, D. S. 1992. Adapting stochastic weather generation algorithms for climate change studies. Climatic Change 22: 67-84.

1999. Interannual variability and extreme-value characteristics of several stochastic daily precipitation models. Agric. and Forest Meteorology 93(3): 153-169.

$\mathrm{Yu}, \mathrm{B}$. 2000. Improvement and evaluation of CLIGEN for storm generation. Trans. ASAE 43(2): 301-307.

Zhang, X. C., M. A. Nearing, L. M. Risse, and K. C. McGregor. 1996. Evaluation of WEPP runoff and soil loss predictions using natural runoff plot data. Trans. ASAE 39(3): 855-863. 